http://dx.doi.org/10.12795/RAA.2012.i02.07

\title{
IDENTIFICACIONES PATRIMONIALES EN CONFLICTO. UN ANÁLISIS A PARTIR DE TRES CASOS EN CATALUÑA
}

\author{
GABRIEL ALCALDE ${ }^{(*)}$, JOSEP BURCH ${ }^{(*)}$, \\ ELISEU CARBONELL ${ }^{(*)}$, GEMMA DOMÈNECH ${ }^{(* *)}$ \\ ${ }^{(*)}$ Institut Català de Recerca en Patrimoni Cultural y Universitat de Girona. \\ ${ }^{(*)}$ Institut Català de Recerca en Patrimoni Cultural.
}

\section{Resumen.}

En los últimos años se observa una creciente participación de la población en los procesos de patrimonialización impulsados antaño desde estamentos académicos o gubernamentales y, más recientemente, por la sociedad civil. Estos procesos no se escapan a los conflictos de intereses y visiones a menudo contrapuestas sobre qué debe ser identificado como patrimonio y sobre cómo deben conducirse dichos procesos. Un buen ejemplo de ello son los procesos de patrimonialización que afectan a áreas concretas del territorio. En este artículo los autores, investigadores del Instituto catalán de investigación en patrimonio cultural, presentan un análisis sobre los modos en que afloran y se enfrentan los conflictos por la patrimonialización de territorios como son una playa urbana situada en la comarca del Maresme, al norte de Barcelona, un importante accidente geográfico como el Cabo de Creus incluido en un Parque Natural y una extensa área rural de la comarca del Ampurdán, en la provincia de Girona, donde se ubica el conjunto arqueológico de Ullastret y que afecta a varios municipios. Con estos tres casos se pretende mostrar la complejidad de las conceptualizaciones patrimoniales y 
los conflictos que ello genera, lo cual en último término expresa una mayor implicación de la sociedad hacia el patrimonio.

Palabras clave: Paisaje, Territorio, Procesos de patrimonialización, Conflicto, Cataluña Abstract.

In recent years, it can be observed an increasing participation of local population in processes of making heritage or "heritagization", formerly driven from academy or government and, more recently, from civil society. But these processes do not escape from conflicts of interest and often conflicting views on what should be identified as heritage and how these processes should be conducted. The patrimonial processes that affect specific areas of the territory are a good example of it. In this article the authors, researchers at the Catalan Institute for Cultural Heritage Research, present an analysis of the ways in which conflicts arise and are faced in three territories: an urban beach located in the Maresme region, north of Barcelona; a major geographical feature such as the Cabo de Creus situated inside a Natural Park; and, a large rural area in the region of Empordà, in the province of Girona, where is located the archaeological site of Ullastret and that affects several municipalities. With these three cases the authors intend to show the complexity of the conceptualizations of heritage and the conflicts this creates, which ultimately expresses a greater involvement of society towards cultural heritage.

Keywords: Landscape, Territory, Processes of making heritage, Conflict, Catalonia

\section{INTRODUCCIÓN: PATRIMONIALIZACIONES DE LOS TERRITORIOS}

Los procesos de patrimonialización y de identificación comportan en algunos casos una cierta unanimidad entre los sectores implicados en relación a los objetivos de conservación y uso que se pretenden alcanzar. En otros casos, sin embargo, existen visiones distintas, e incluso contrapuestas, producidas por la aplicación de distintos conceptos ideológicos, profesionales o relacionados con el significado de los elementos patrimoniales, o consecuencia de intereses de diferentes tipos. Esta segunda situación se origina a menudo cuando los procesos de patrimonialización se producen sobre espacios y territorios y en esta situación la implicación de la sociedad es, en muchas ocasiones, importante.

Una muestra deesta implicación la encontramos en las plataformas dedefensa del territorio, que entre sus objetivos tienden a considerar el mantenimiento de un determinado espacio desde ópticas patrimoniales ("Salvemos") o la oposición a determinadas actuaciones consideradas agresivas para espacios entendidos como patrimoniales ("No"), que según Joan Nogué "reivindican aquello propio, el territorio y el paisaje y el patrimonio autóctono amenazados por el crecimiento imparable de la urbanización y de las infraestructuras" 
(Nogué, 2010: 35-36). Desde los últimos años del siglo XX, la defensa del patrimonio cultural se sitúa pues también en el marco de actuación de los nuevos movimientos sociales (Montiel, 2004, 2008), hecho que ha favorecido en gran medida la participación de la sociedad en las decisiones patrimoniales.

En los últimos años se ha venido incrementando la implicación de la sociedad con el patrimonio y se ha venido asumiendo el concepto de patrimonio e incorporándolo a los discursos y prácticas de reificación de las identidades y derechos colectivos en un ejercicio de carácter casi sagrado, como Roigé y Frigolé (2010) han sugerido recientemente al plantear que el patrimonio se ha convertido hoy en día en una especie de nuevo culto moderno. Este hecho ha conducido a una interpretación y, especialmente, a una interiorización del patrimonio rica, variada y llena de matices. Esta riqueza se exterioriza más claramente, y a menudo con mayor rotundidad, cuando se trata de espacios, paisajes y territorios, puesto que estos constituyen los elementos probablemente más cotidianos para la población, de los que emana una "identidad vivida", siguiendo el razonamiento de Ignasi Terradas (2004), es decir: "el paisaje como percepción y recuerdo de vida"; y en esta riqueza se sitúan también posturas enfrentadas.

Para contribuir al análisis de esta situación de conceptualizaciones diferentes del patrimonio cultural, plantearemos una aproximación a partir de tres casos distintos situados en la zona costera catalana, la playa de Sant Pol de Mar, el Club Med de Cap de Creus y el Conjunto Arqueológico de Ullastret. Se trata de tres situaciones recientes de legitimaciones patrimoniales de características diversas, en el primero de ellos la principal oposición se produce entre sectores que valorizan el mantenimiento de un espacio natural en su situación actual frente a sectores que priorizan su urbanización; el segundo opone principalmente dos posiciones distintas de interpretación de lo que es el patrimonio cultural, una hegemónica basada en los valores del patrimonio natural y otra, minoritaria, que se basa en valoraciones paisajísticas arquitectónicas; finalmente, en la tercera situación observaremos como una buena parte de los actores locales se oponen a una protección arqueológica de un determinado espacio apoyada en criterios de carácter científico y académico.

\section{LA PLAYA DE LAS BARCAS Y EL PASEO MARÍTIMO}

Una mañana de julio de 2007 en Sant Pol de Mar, un tranquilo pueblo de apenas cinco mil habitantes de la costa catalana, los primeros en ir a la playa se encontraron con unos operarios instalando una valla publicitaria del Ministerio de Medio Ambiente que anunciaba el comienzo inminente de las obras de rehabilitación del frente marítimo, con un presupuesto adjudicado de dos millones de euros. Al cabo de pocos días el cartel fue objeto de grafitis de protesta donde se leía: No más piedras.

El proyecto de rehabilitación del frente marítimo consistía en construir un muro 
de protección para la vía del tren, que recorre la comarca paralela a la costa, con una plataforma de 4 metros de anchura y 400 de longitud. Esta plataforma sería habilitada en forma de paseo peatonal, con sendos pasos subterráneos de acceso a la playa a cada extremo. La playa afectada se sitúa frente al núcleo urbano del municipio y se conoce popularmente como "playa de las barcas" puesto que, hasta los años setenta del pasado siglo, era la base de la importante flota pesquera de la población.

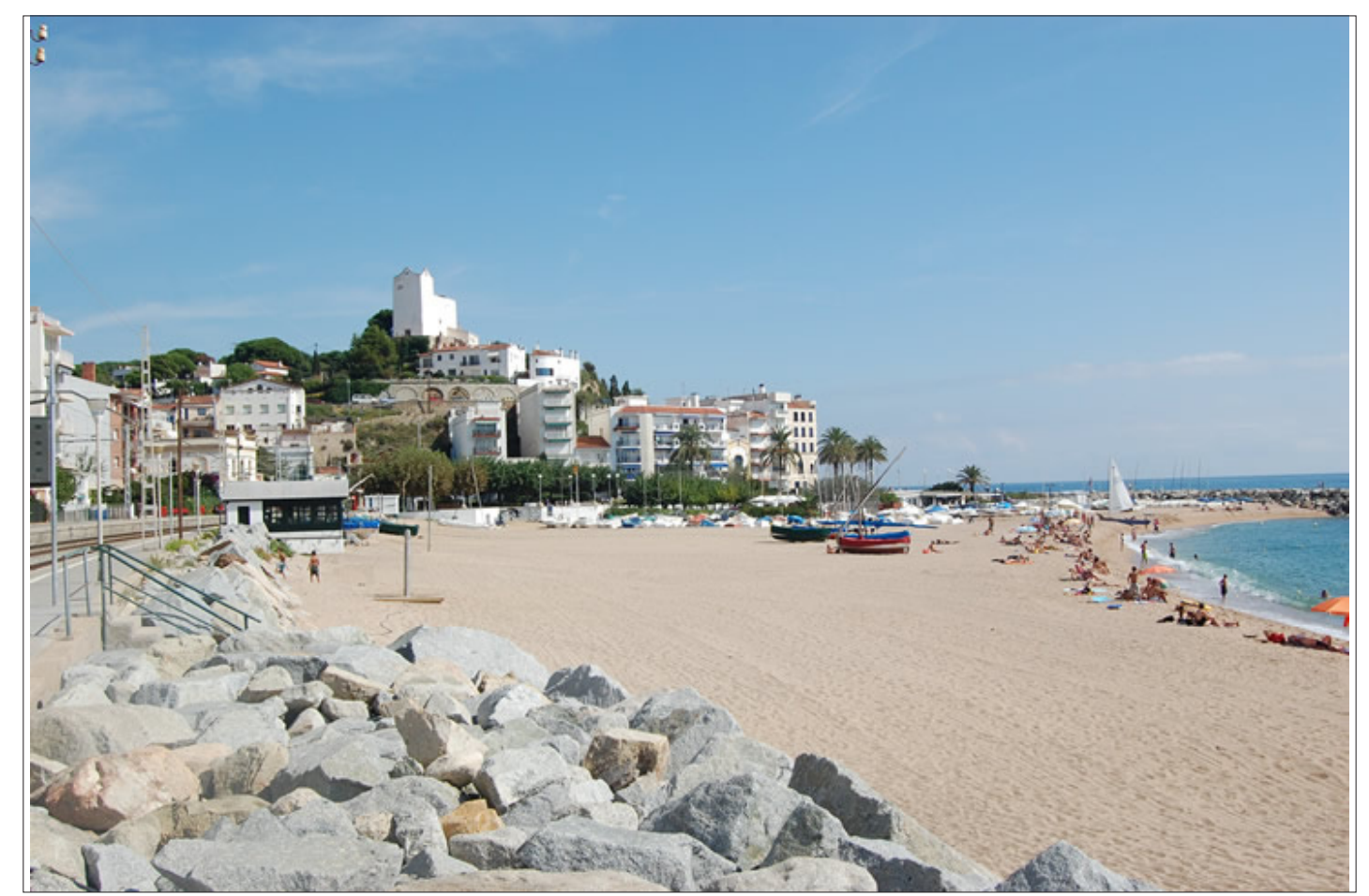

Figura 1.

Figura 1. La "Playa de las barcas" de San Pol de Mar. Foto: ICRPC-Eliseu Carbonell

Los opositores al proyecto empezaron a organizarse en forma de plataforma ciudadana en defensa de la playa, siguiendo un guión que parece estandarizado, como mostró Oriol Nel.lo (2003) en su trabajo sobre los movimientos ciudadanos de defensa del territorio en Cataluña. La movilización contra el proyecto rápidamente adquirió un aire de conflicto. Uno podía escuchar a diario encendidas discusiones entre defensores del proyecto y "defensores de la playa"-como se autodenominaban- en bares, tiendas e incluso en la calle. Resulta un tanto difícil llegar a identificar quien se posicionó a favor y quien en contra del proyecto. A nivel municipal, el gobierno y la oposición estaban claramente enfrentados por esta cuestión. Pero a nivel popular resulta más difícil discernir quien era quien, puesto que en la plataforma contra el proyecto había conocidos comerciantes locales que en principio deberían estar a favor del desarrollo turístico y, en el lado opuesto, a favor del proyecto había militantes ecosocialistas que en principio parecería 
que se posicionarían en contra de la "agresión" al litoral que suponía dicha obra. Se organizaron asambleas, manifestaciones, happenings, recogidas de firmas, etc. Los otrora insulsos plenos municipales pasaron a ser multitudinarios, con griterío, abucheos y descalificaciones personales dirigidas sobre todo al alcalde y al concejal de urbanismo. La prensa catalana también se hizo eco de las protestas, "La política destrozará la playa” o "Consigna: salvar la playa”, fueron algunos de los lacónicos titulares que publicaron aquél verano periódicos como Avui o El Punt ${ }^{1}$.

Los opositores al proyecto alertaban que la playa desaparecería enterrada bajo las piedras de un muro que, según ellos, tenía por único objeto proteger la vía del tren de los temporales marítimos sin tomar en cuenta el impacto que ello podría causar en la playa. En efecto los temporales, fuertes sobretodo en otoño, pueden llegar a provocar la interrupción de la circulación de trenes. Esta es la razón fundamental por la que se vio la necesidad de elaborar dicho proyecto. Se trata de un problema irresuelto desde que se creó esta línea litoral de ferrocarril en la segunda mitad del siglo XIX, la proximidad de las vías al mar provoca socavones o cubre los raíles de arena cuando el temporal golpea la costa. Los defensores del proyecto argumentaban la necesidad de tal protección y las ventajas del paseo marítimo que surgiría de dicha protección para un pueblo que vive principalmente del turismo residencial.

Después de un tenso verano, a finales de septiembre se llegó a un acuerdo entre gobierno y oposición municipal, solicitando la suspensión temporal del proyecto a la Demarcación de Costas de Cataluña y la creación de una comisión especial con la asesoría de técnicos de la Universidad Politécnica de Cataluña, que ayudaran a encontrar una solución a la protección de las vías que no perjudicara a la playa. Pero la solución llegó de forma inesperada antes de cumplirse el periodo de moratoria concedido, cuando Costas comunicó al Ayuntamiento que suspendía de forma definitiva la ejecución del proyecto. La noticia fue recibida con evidente euforia por parte de los opositores, que lo interpretaron como una victoria de su presión. Por el contrario el ayuntamiento de Convergència i Unió lo interpretaba, en un comunicado, como el rescate de una inversión del Estado para destinarla a otras actuaciones en el contexto del debate sobre el déficit de las infraestructuras en Cataluña.

Históricamente la playa ha desarrollado un rol muy importante en esta población. Hasta los años setenta del siglo pasado era la base de su importante flota pesquera. Sabemos que en los años cuarenta, 300 de sus 1.600 habitantes eran pescadores (Alegret y Nadal, 1987: 139) a lo que habría que añadir un número similar de mujeres que se dedicaban a la reparación de redes, venta de pescado y conserva estacional (el mismo propietario de una fábrica textil trasladaba a las trabajadoras a otro local situado en frente, donde

1. G. Aguilera, "La política destrossarà la platja de pescadors", Avui, 29.02.2007; T. Márquez, "Consigna: salvar la platja de Sant Pol. Rebuig veïnal a un projecte de passera", El Punt Diari, 15.08.2007 
se sazonaban sardinas cuando las capturas eran considerables). A partir de la eclosión del turismo residencial, la playa ha sido y sigue siendo uno los principales atractivos del pueblo.

Pero lo que más llama la atención del movimiento que surgió en contra del proyecto de rehabilitación del frente marítimo es la constante alusión a la identidad del pueblo fundamentada en su playa. Hay una imagen que ilustra muy bien esto. Al término de una manifestación que finalizó frente al ayuntamiento, donde junto a pancartas en contra del proyecto se portaban banderas catalanas con crespones negros, se depositó ante la puerta del consistorio un cubo repleto de arena de la playa en el que se clavó un letrero que, en forma de epitafio, decía: "La Playa, 1599-20072". 1599 es la fecha que pone en las enciclopedias como nacimiento del pueblo. Con ese epitafio la playa, que es un elemento del paisaje con una escala temporal geológica, se hace coincidir con la escala temporal de la cronología histórica, al identificar el origen de la playa con el nacimiento mismo del pueblo. De modo que si la playa nace con el pueblo, si muere la playa morirá el pueblo. La identificación entre la playa y el pueblo no puede ser más profunda. Otros elementos que sitúan la playa como receptáculo de la identidad local se basan en las experiencias del paisaje vivido recogidas en numerosos testimonios orales, la playa como escenario de instantes fundacionales de la biografía íntima de sus habitantes, la playa como plaza pública donde cada verano se instala el entoldado de la Fiesta Mayor, donde los grupos de amigos y familiares se reúnen a cenar la noche de los fuegos artificiales, donde el chiringuito se conocía popularmente como "el tumulto" por el gran número de gentes y encendidas tertulias que acogía en verano, etc.

En la última década, además, la playa es escenario de otro tipo de experiencia vivida, ligada ésta al patrimonio marítimo. Este proceso está siendo llevado a cabo por una asociación de amantes de la vela latina y la navegación tradicional, nacida el año 2001 con el objetivo de "promover la conservación y difusión del patrimonio marítimo", según se recoge en su página web $w^{3}$. Actualmente cuenta con medio centenar de socios que se han encargado de la restauración de varios laúdes de pesca de madera que habían sido descuidados por sus antiguos dueños y a los que, una vez restaurados, se les dota del aparejo para navegar a vela latina, vela que estas barcas no habían llevado nunca pero que evoca un imaginario pesquero tradicional en sus nuevos propietarios. La asociación, además, ha llevado a cabo la construcción de una réplica de un barco sardinero del siglo XIX, de diez metros de eslora que se ha convertido en el buque insignia que representa a la población en los diversos encuentros de navegación tradicional que se celebran a lo largo de la costa catalana. También organizan en la playa varias actividades relacionadas

2. T. Márquez, "Consigna: salvar la platja de Sant Pol. Rebuig veïnal a un projecte de passera", El Punt Diari, 15.08.2007

3. http://www.atotdrap.cat/node/2 [Consulta: 9/01/2012]. 
con el patrimonio marítimo, como por ejemplo demostraciones de pesca tradicional y subasta de pescado "a la antigua". Finalmente, el proyecto más emblemático de la asociación ha consistido en la restauración de una pequeña construcción situada en la playa, destinada originariamente a albergar los dos motores que se usaban para remolcar las barcas en la playa, conocida popularmente como "la caseta de la maquinilla" y que ha sido transformada en un pequeño museo o "centro de interpretación" -según la denominación oficial- del patrimonio marítimo de la localidad. Esta caseta era usada anteriormente por los pescadores deportivos, generalmente jubilados -pescadores y no pescadores-, que mantienen un pequeño bote a motor en la playa.

La inauguración del centro de interpretación coincidió, en verano del 2007, con el período más intenso de confrontación a raíz del proyecto de rehabilitación del frente marítimo. Algunos de los opositores más activos propusieron en un foro de internet aprovechar la presencia de autoridades que se reunirían con motivo del acto de inauguración para hacer oír su voz. En la convocatoria se llamaba a "todos los que no queremos más PIEDRAS y si queremos ARENA" a boicotear el acto de inauguración porqué "cuando los temporales se lleven la poca arena que nos queda, ¿dónde vararán sus barcas estos espabilados?”. Este comentario es sintomático de un ambiente de competencia por la apropiación simbólica y espacial de la playa. Los promotores del proyecto de patrimonialización de la playa se sienten herederos de los antiguos pescadores y con ello legitimados para devolver a la playa su antiguo aspecto de playa de pescadores, a sabiendas de que su proyecto entra en conflicto con otros usos sociales de la playa, como por ejemplo el uso lúdico por parte de los turistas veraneantes, pero también de los pescadores no profesionales propietarios de los botes de fibra de vidrio, la mayoría gente mayor, que eran los únicos pescadores que quedaban en la playa desde la desaparición de la pesca profesional en los setenta y que entran en clara competencia con las embarcaciones restauradas por el uso del espacio central de la playa. Pero, finalmente, el proyecto patrimonializador genera conflicto por la competencia en lo referido al uso de la playa en los discursos sobre la identidad local frente a las amenazas externas que provienen del proyecto de rehabilitación del frente marítimo. Porqué si algo puso de manifiesto el conflicto aquí reseñado es que anteponer la playa al paseo marítimo equivalía para unos a defender el pueblo y para otros a querer apoderarse de lo común.

\section{EL CLUB MED Y EL PARC NATURAL DE CAP DE CREUS}

Cien años después del bautizo de la Costa Brava poco queda de ese paisaje extraordinario. Después de haber sido en buena parte desfigurado por la urbanización desbocada, son muchas las voces que, con diferentes intensidades y matices, reclaman cambios y reorientaciones ${ }^{4}$. De momento, sin embargo, los poderes públicos persisten en la

4. La discusión sobre el futuro de la Costa Brava reunió, el año 2004, a expertos de todos los ámbitos (AAVV, 2005). 
promoción de la actividad constructiva como motor económico, la ampliación de la capacidad hotelera y de los puertos deportivos. Hasta ahora la atención protectora se ha fijado en la preservación integral de pequeñas porciones antes que en el desarrollo armónico de todo el litoral. De acuerdo con esta tendencia, el 14 de julio de 2009 comenzaba el derribo del Club Mediterranée, paradójicamente una de las urbanizaciones de la Costa Brava mejor integradas paisajísticamente en el entorno. "Una de las pocas muestras de urbanización respetuosa con el entorno que podemos encontrar en el litoral de la Costa Brava", según Sílvia Musquera (2004: 340), conocedora de la arquitectura nacida del turismo. Sin embargo, el complejo diseñado y ejecutado en los años sesenta por los arquitectos Jean Weiler y Pelayo Martínez Paricio, con la estrecha implicación del artista Salvador Dalí (Musquera, 2004), tuvo la mala fortuna de haber quedado enclavado en el corazón del Parque Natural del Cap de Creus, creado en 1998 como una de las joyas de la preservación medioambiental catalana.

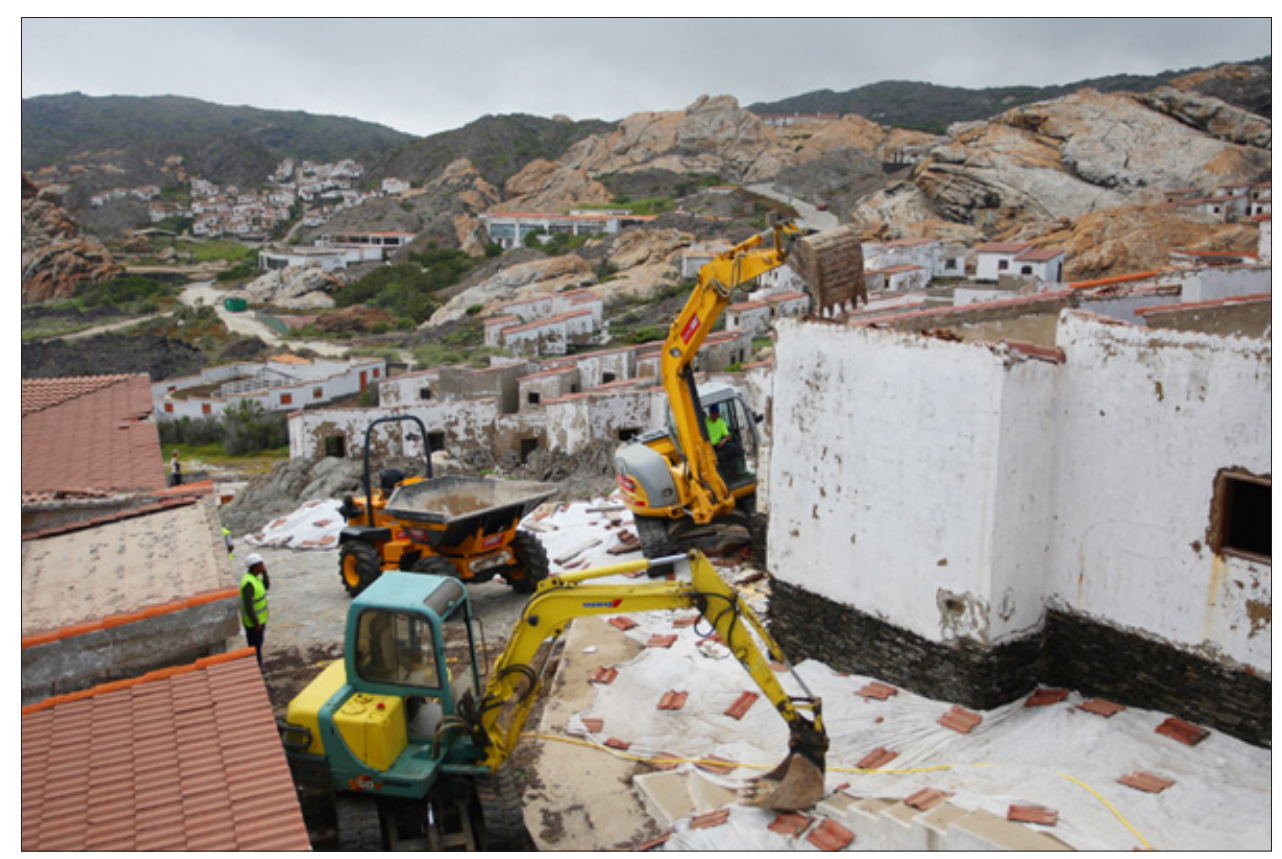

Figura 2.

Figura 2. Trabajos de desmantelamiento del Club Med. Foto: ICRPC-Lluís Serrat

El derribo de los bungalows de la ciudad de vacaciones que el Club Mediterranée tenía en el paraje de Cap de Creus, ponía punto y final a una historia de más de diez años de negociaciones. El 4 de enero de 2001 el Ministerio de Medio Ambiente hacía pública su voluntad de comprar el complejo para desmantelarlo y regenerar la zona, que había sido declarada parque natural tres años antes. Pero la intención de la administración topaba frontalmente con los intereses de los propietarios, que pretendían reconvertir el centro 
en un complejo ecológico adaptado al espacio geográfico que ocupaba ${ }^{5}$. Para avalar la operación, el Estado aportaba un estudio elaborado por el biólogo Alexandre Omedes que atribuía el Club Med “importantes daños medioambientales en los últimos 40 años” y que consideraba que "sólo la compra, demolición y restauración para integrarse en el ecosistema permitirá la recuperación y expansión de especies existentes y la posible reintroducción de especies extinguidas recientemente ${ }^{6 "}$. A partir de ese momento, éste será el discurso oficial que repetirán políticos y medios de comunicación. Recordemos que la declaración de Parc Natural y por lo tanto, la necesidad de regeneración del espacio, se produjo casi cuarenta años después de la construcción del campamento de vacaciones.

La lucha por hacer desaparecer el Club Med se convertirá en el símbolo de la recuperación de la Costa Brava, sin tener en cuenta que constituía el mejor ejemplo de urbanización turística integrada paisajísticamente en el entorno, de las que en los últimos cincuenta años se han edificado en este rincón del mediterráneo. Pelayo Martínez, arquitecto figuerense buen conocedor del lugar, y Jean Weiler, arquitecto de la empresa, estudiaron la topografía y climatología del lugar para diseñar unas estructuras bien adaptadas al entorno. Unas construcciones que se intentaron mimetizar con el territorio tal y como escribía uno de los autores: "El lugar se compone de unos elementos (...) de poco volumen que no fue muy difícil camuflar, los agrupamos en pequeñas unidades preocupándonos que, vistas desde el mar, dieran impresión de un vuelo de gaviotas" (Musquera, 2004: 321). La suma del talento de Weiler, considerado pionero en la práctica de la arquitectura sostenible, y de la estimación que Pelayo Martínez sentía por el paisaje del Cap de Creus, serán los que guiarán la redacción del proyecto.

El Club Med de Cadaqués había abierto sus puertas el 9 de junio de 1962 con 200 hectáreas de terreno y 350 bungalows, que a lo largo de más de 40 años convirtieron el lugar en un espacio reservado a los turistas extranjeros que venían a Cataluña para disfrutar de uno de los paisajes más fascinantes de la Costa Brava. Precisamente su situación paradisíaca, en medio del actual Parque Natural del Cap de Creus, ha supuesto su desaparición. Los defensores del derribo han argumentado que la urbanización ocupaba uno de los espacios de mayor valor medioambiental del parque, y que su presencia impedía la recuperación de los ecosistemas marinos y terrestres. En el citado informe encargado por el Estado, se exponía la previsión de que con demolición del complejo, el Parque Natural del Cap de Creus se situaría entre los espacios naturales "de primer orden mundial".

En la defensa del desmantelamiento del Club Med aparecen, más allá de los valores medioambientales ligados a la creación de la reserva natural, otros factores nada

5. C. Vilà, "Costes vol adquirir el Club Med per desmantellar-lo i el complex no ven", Diari de Girona, 04.01.2001, p. 5.

6. R. Carmona, "Un estudi atribueix al Club Med importants danys mediambientals en els darrers 40 anys”, El Punt, 14.01.2001, p. 6. 
desdeñables. Uno es, el carácter forastero de sus propietarios y de sus usuarios, que lleva a la prensa a tildar el complejo como "el Gibraltar catalán". Y el otro, la época de construcción y su identificación con "el descontrol urbanístico del franquismo". Por todo ello, el Club Med se convierte en un símbolo de todos los males que sufre la Costa Brava y los políticos progresistas toman este derribo como símbolo de los nuevos tiempos. Joan Boada, entonces portavoz parlamentario de Iniciativa per Catalunya Verds, valoraba la adquisición como "una noticia excelente, ya que después de tanto tiempo un gobierno se ha atrevido a destruir uno de los emblemas de lo que no debería haberse hecho nunca en la Costa Brava" y, continuaba "este derribo será todo un símbolos. El carácter emblemático que se quería dar al hecho, queda perfectamente reflejado en la prensa, que el 22 de diciembre de 2005, coincidiendo con la formalización de la compra, titula: "El ejemplo del Club Med'.

A lo largo del proceso surgen algunas voces disconformes con la propuesta de derribo total de las instalaciones. Más allá de los que reclamaban mantener algunas estructuras para ser reaprovechadas por los visitantes del parque ${ }^{10}$, la principal protesta la protagonizan los pescadores de la zona. En diciembre de 2002, apenas iniciados los trabajos de derribo del embarcadero construido en Cala Culip, los pescadores encabezados por la Cofradía de Cadaqués se manifiestan para reclamar su mantenimiento, pues era el único refugio para las embarcaciones en muchos kilómetros y el único lugar para acceder a los servicios de emergencia en caso de accidentes marítimos. El conflicto evidencia el profundo desacuerdo entre los responsables del parque y los vecinos de la zona que presentaban un manifiesto pidiendo la dimisión de la directora del parque esgrimiendo que "nunca ha existido la más mínima colaboración de la población y entidades cívicas, culturales y de los profesionales del mar de Cadaqués, marginándolos constante y sistemáticamente ${ }^{11}$.

Tres años más tarde, coincidiendo con el anuncio del gobierno del acuerdo de compra ${ }^{12}$, reaparecen las voces que reclamaban la conservación de una parte de las instalaciones para ubicar el centro de interpretación del parque y la recepción de visitantes. Por primera vez se apela, aunque muy tangencialmente, al interés arquitectónico del conjunto:

7. "Els privilegis del Club Mediterranée", Diari de Giorna, 13.06.2002, p. 18.

8. R. Carmona, "Tots els partits reclamen un enderroc ràpid del Club Med, però acceptarien mantenir algun edifici al servei del parc", El Punt, 18.08.2005, p. 3.

9. P. Abarca, "L'exemple del Club Med", El Punt, 22.12.2005, p. 15.

10. R. Carmona, "El PSC considera viable conservar algunes de les estructures del Club Med", El Punt, 15.02.2001, p. 9.

11. C. Vilà, "Els pescadors protesten per l'enderroc de l'embarcador del Club Mediterranée", Diari de Girona, 22.12.2002, p. 8. Bataller, Marc. "Campanya veïnal per mantenir l'amarrador del Club Med perquè és l'únic en molts quilòmetres", El Punt, 22.12.2002, p. 22.

12. R. Carmona, "El govern espanyol tanca un acord per comprar el Club Med de Cadaqués per quatre milions", El Punt, 17.08.2005, p. 2. 
"Arquitectónicamente tiene cierto buen gusto y algún espacio puede tener utilidad para un turismo medioambiental" afirmaba el diputado de Convergència i Unió Jordi Xuclà ${ }^{13}$. Una opinión, la de la reutilización de algún edificio y del amarre en la que hay consenso político, pero que cuenta con la oposición frontal de la plataforma ecologista Salvem l'Empordà y de los responsables del Parque Natural del Cap de Creus ${ }^{14}$. En este punto del debate, el Col-legi d'Arquitectes de Catalunya se posiciona a favor de la conservación apelando al valor arquitectónico de la obra y a su integración en el paisaje ${ }^{15}$. Pero iniciados los trabajos de desmantelamiento se produce un silencio absoluto entre los defensores del patrimonio arquitectónico. En estos años, únicamente hemos podido recoger la crítica irónica de un periodista, que reproducimos a continuación. El 14 de enero de 2007, Xevi Xirgo escribía “... estamos eufóricos porque hemos recuperado un espacio de un valor geológico y paisajístico altísimo que, por culpa del Club Med, se había edificado. Dicen que fue un crimen, un atentado ecológico y no sé cuántas cosas más. Yo, qué quieren que les diga: ojalá hubieran edificado una decena, de Clubes Med, en el litoral catalán. Porque si no, ahora ya me dirán cómo lo hacemos, para derribar los bloques de pisos de diez y más plantas en primera línea de mar en Lloret o Platja d'Aro que se construyeron por las mismas fechas, y que me suscitan una impresión más desfavorable de la que me daba el Club Med"16.

\section{EL POBLADO IBÉRICO DE ULLASTRET Y SU ENTORNO}

El poblado ibérico del Puig de Sant Andreu de Ullastret es uno de los conjuntos arqueológicos más visitados en Cataluña. Según los datos estadísticos del Departamento de Cultura del gobierno catalán, en el año 2010 el número de visitas alcanzó la cifra de 28.955, con un promedio en el último lustro de 33.284 por año. Además, según un estudio realizado recientemente, este yacimiento es uno de los más conocidos entre los turistas que frecuentan la Costa Brava (Alcalde et al., 2011: 214), uno de los principales destinos turísticos de Cataluña (Catalunya turística en xifres 2010, 2011).

Las primeras referencias escritas de este conjunto arqueológico fechan de 1931 aunque las primeras excavaciones no tuvieron lugar hasta el 1947 y con carácter anual a partir de 1952. Fueron financiadas por la Diputación Provincial de Girona, institución que adquirió entre 1954 y 1957 los terrenos donde se ubica el yacimiento. Posteriormente, en el año 1961 se inauguró en el mismo lugar un museo monográfico vinculado a los restos

13. R. Carmona "Partidaris de conservar-ne una part", El Punt, 17.08.2005, p. 2. O. Mas "El govern vol que el Club Med de Cadaqués s'hagi enderrocat a l'estiu i estudia mantenir-hi alguna edificació", $E l$ Punt, 11.01.2006, p. 7

14. R. Carmona, "Tots els partits reclamen un enderroc ràpid del Club Med, però acceptarien mantenir algun edifici al servei del parc", El Punt, 18.08.2005, p. 3.

15. J. Puigbert, "Arquitectes defensen la conservació d’alguns dels espais del Club Med de Cadaqués”, El Punt, 08.10.2005, p. 10.

16. X. Xirgo, "El Club Med”, El Punt, 14.01.2007, p. 5. 
arqueológicos. En aquella misma época se localizó a escasos metros del Puig de Sant Andreu, el poblado ibérico de la Illa d'en Reixac, que fue objeto de intervenciones arqueológicas entre los años 1965 y 1967 (con la compra de los terrenos correspondientes por parte de la Diputación Provincial) y, más tarde, entre 1976 y 1995. Ya en la década de los años 70 diversos trabajos de prospección permitieron localizar en su entorno diversos yacimientos arqueológicos. En el año 1982 se descubrió la necrópolis ibérica del Puig d’en Serra, en el municipio de Serra de Daró, en unos terrenos de propiedad comunal. En el año 1992 la gestión de los dos poblados ibéricos, Puig de Sant Andreu y Illa d'en Reixac, y el museo correspondiente, fue traspasada a la Generalitat de Catalunya, que renovó el museo entre los años 1995 y 1996 (Martín, 1997: 5-7). Actualmente, poblados ibéricos y museo forman parte del conjunto de equipamientos y yacimientos arqueológicos que conforman el Museu Arqueològic de Catalunya con rango de museo nacional.

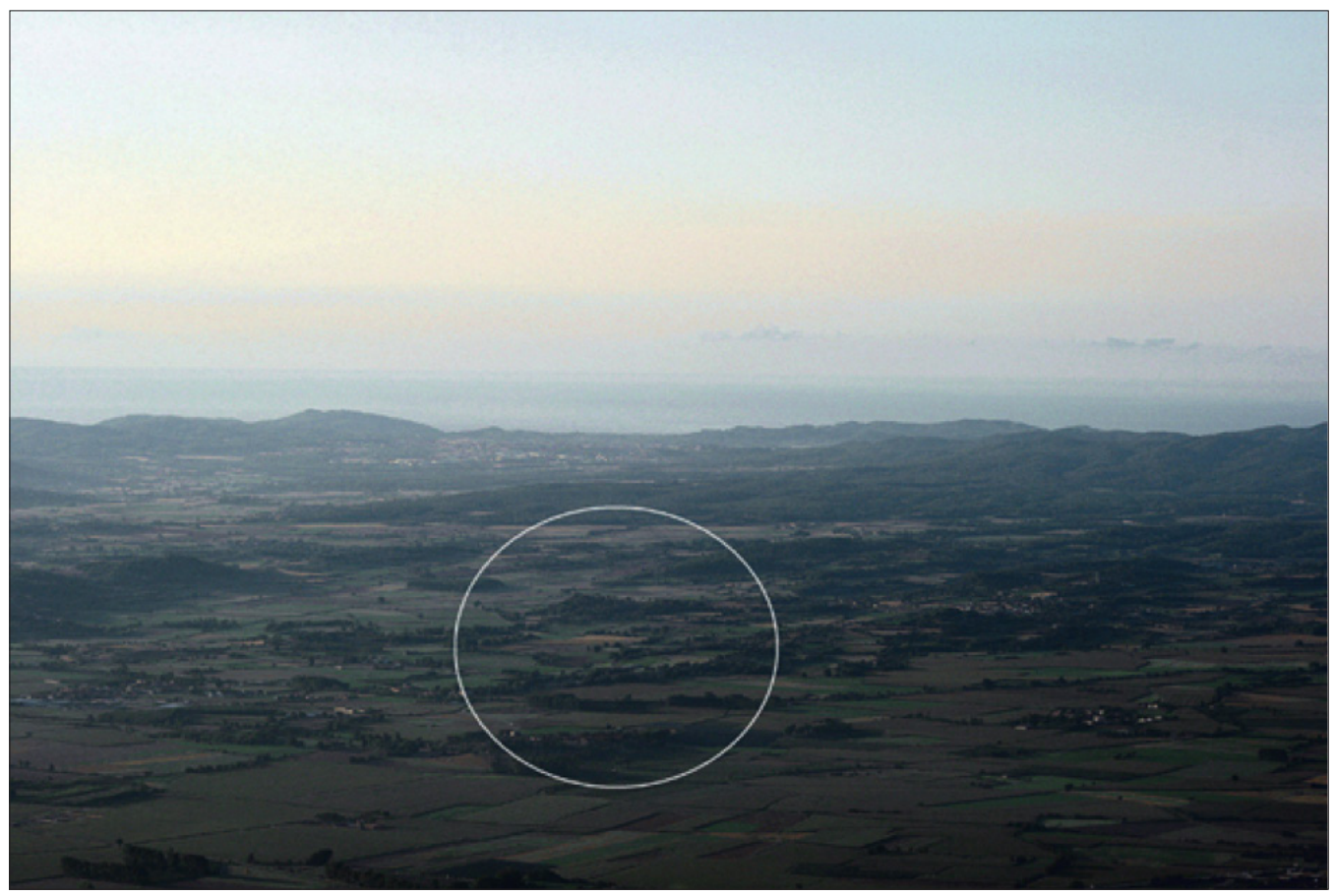

Figura 3.

Figura 3. El Conjunto Arqueológico de Ullastret. Foto: ICRPC-Josep Burch

Este conjunto arqueológico se ubica dentro de los límites del municipio de Ullastret, de 268 habitantes y de carácter muy rural. Esta situación es paralela a la que hallamos en los municipios colindantes y afectados también por una de las categorías de protección previstas en la ley catalana de patrimonio cultural, la declaración de Bien Cultural de Interés Nacional (BCIN): Serra de Daró con 209 habitantes y Fontanilles con 167 y algo menos Forallac con 1.785 habitantes.

Durante el mes de abril de 2005 se iniciaron los trámites para declarar BCIN al conjunto arqueológico de Ullastret mediante la publicación en el Diari Oficial de la Generalitat de 
Catalunya de la incoación de un expediente de declaración ${ }^{17}$. Hasta aquel momento solo estaba protegido el poblado ibérico de Ullastret ${ }^{18}$. A partir de la declaración elárea protegida se ampliaba considerablemente, afectando un territorio más amplio englobado en los municipios de Ullastret, Serra de Daró, Forallac i Fontanilles, todos ellos pertenecientes a la comarca del Baix Empordà. Los medios de comunicación ya mencionaron en aquel momento que esta declaración podía afectar la construcción de una planta de residuos que se pretendía ubicar cerca de uno de los yacimientos incluidos en la declaración, el de los Clots de Sant Julià. Estos terrenos habían sido adquiridos en su totalidad por una sociedad en el año 2003 y su calificación era de zona de servicios ${ }^{19}$. Los Clots de Sant Julià se considera uno de los principales puntos de extracción de piedra para su uso en la construcción de diversos edificios de los poblados ibéricos del Puig de Sant Andreu y de la Illa d'en Reixac, ambos en Ullastret y en numerosos edificios de época ibérica y romana además de una utilización continuada a lo largo de la historia de la comarca del Baix Empordà. Ya en los años 2003-2004 la entidad SOS Empordanet (una asociación dedicada a la defensa del patrimonio cultural y natural de esta zona del Ampurdán) había realizado un manifiesto y recogido unas 3.000 firmas contra la construcción de la planta de tratamiento de residuos y la petición de su traslado a un polígono industrial ${ }^{20}$. También el Consell Comarcal del Baix Empordà ya había manifestado con anterioridad su interés en la protección de los Clots de Sant Julià̄ ${ }^{\bigotimes}$.

El 3 de octubre de 2006 mediante un acuerdo del gobierno de la Generalitat de Catalunya ${ }^{21}$ se procedía a la declaración de $\mathrm{BCIN}$, la máxima protección que establece la Ley del Patrimonio Cultural Catalán aprobada en el año 1993, con la categoría de zona arqueológica. En la memoria que acompañaba el acuerdo de gobierno se consideraba el conjunto ibérico de Ullastret como uno de los conjuntos arqueológicos más significativos de la cultura ibérica y con un gran interés históricoarqueológico. También se destacaba el conjunto arqueológico como el asentamiento ibérico más conocido y excavado de

17. "Resolució CLT/1203/2005, de 5 d’abril, per la qual s'incoa expedient de declaración de bé cultural d'intereès nacional en la categoría de zona arqueológica i entorn de protección, a favor del Conjunt arqueològic d'Ullastret (Ullastret, Serra de Daró, Forallac i Fontanilles, al Baix Empordà), i sobre un período d'informació pública”. Diari Oficial de Generalitat de Catalunya (26.04.2005, 4.371, p. 11.066)

18. "El Departament de Cultura inicia els tràmits per declarar bé cultural d'interès nacional el conjunt arqueològic d'Ullastret”. El Punt, 25.04.2005.

19. "Els Clots de Sant Julià tindrán un entorn amb tres nivells de protecció". El Punt, 10.01.2007.

20. "La Fundació territorio i Paisatge s'interessa per la protección dels Clots de Sant Julià". El Punt, 29.07.2007.

21. ACORD GOV(132/2006, de 3 d'octubre, del Govern de la Generalitat de declaració de bé cultural d'interès nacional, en la categoria de zona arqueològica i entorn de protecció, a favor del conjunt arqueològic d'Ullastret (Ullastret, Serrà de Daró, Forallac i Fontanilles). Diari Oficial de la Generalitat de Catalunya, 23.10.2006, 4.745, p. 44.395. 
Cataluña a lo que se añadía su carácter monumental y capacidad de musealización, entendida esta como un "ejemplo de museo al aire libre en un entorno paisajístico de altos valores culturales". La misma memoria destacaba la interrelación entre los yacimientos con su entorno rural, poco antropizado y evocador del existente en época antigua.

Este conjunto de motivos determinaron que la declaración como BCIN no se circunscribiera exclusivamente a los poblados más conocidos (Puig de Sant Andreu e Illa d'en Reixac en Ullastret) sino a un conjunto de yacimientos agrupados en seis zonas que conformaban un BCIN discontinuo con un entorno de protección contiguo. La elección de este perímetro de protección se estableció a partir de "criterios patrimoniales, visuales, ambientales y de paisaje urbano con la finalidad de controlar las relaciones entre yacimiento y espacio natural inherente y las intervenciones que en él se realizan”22.

Pocos días después de la declaración el alcalde de Forallac criticaba a la Generalitat en tanto que se había defendido "entidades como SOS Empordanet que lo que hacen, en el fondo, es preservar los intereses de unos particulares. Y me sabe mal que la Generalitat juegue en defensa de estos intereses", además de acusarla de falta de diálogo ${ }^{23}$.

A su vez, SOS Empordanet, a pesar de celebrar la declaración, lamentaba que el entorno de los Clots de Sant Julià quedaba desprotegido, especialmente en aquellos espacios donde se pretendía instalar la planta de reciclaje de residuos antes mencionada ${ }^{24}$ tal y como había pretendido mediante la presentación de diversas alegaciones durante el proceso de la declaración, las cuales finalmente habían sido rechazadas ${ }^{25}$. No obstante, SOS Empordanet apelaba a una reunión en la que la Dirección General de Patrimonio de la Generalitat de Cataluña se comprometía a iniciar un proceso de revisión una vez se hubiera procedido a la declaración definitiva ${ }^{26}$.

Efectivamente, pocos días después, el 24 de noviembre del mismo año de 2006 se incoaba un expediente de modificación de la delimitación del entorno de protección del conjunto

22. Todas las citas textuales incluidas en el cuerpo del texto han sido traducidas del catalán por los autores.

23. "L'Alcade de Forallac diu que se l'ha menyspreat en tot el procés delBCIN d'Ullastret". El Punt, 06.10.2006.

24. "El govern dóna protecció al jaciment arqueolòic d’Ullastret i el seu entorn” . El Punt, 04.10.2006.

25. "La Generalitat desestima fer una zona de protecció als Clots de Sant Julià de Forallac". El Punt, 18.08.2005.

26. "SOS Emprodanet apel-la a un compromís de Patrimoni Cultural" (2006, 5 d'octubre), El Punt, 05.10 .2006 
arqueológico de Ullastret ${ }^{27}$. Concretamente, se procedía a la creación de un entorno de protección de la zona VI para garantizar la preservación de la cantera Clots de Sant Julià, de propiedad privada, y además se creaba un Espacio de Protección Arqueológica $(\mathrm{EPA})^{28}$ como un segundo cinturón de seguridad externo mediante una figura que prevé la actual Ley del Patrimonio Cultural Catalán. La zona protegida se extendía por un área de unas 20 a 30 hectáreas de extensión, comprendía zonas de extracción de piedra, tumbas prehistóricas y zonas de bosque que se encontraban a poca distancia de la planta de residuos ${ }^{29}$.

Como prevé la Ley del Patrimonio Cultural Catalán se notificaba la resolución a los interesados y a los ayuntamientos de Ullastret, Serra de Daró, Forallac y Fontanilles además de abrir un periodo de exposición pública durante el cual se podían presentar alegaciones, tal y como sucedió.

Paralelamente se realizaba una celebración de la declaración en el Museo Arqueológico de Ullastret que reunía a un centenar de personas y en la que su directora resaltaba los efectos positivos a largo término y la protección no solo del propio yacimiento sino de un entorno "fantástico, rural y bien conservado" ${ }^{30}$.

A principios del año 2007 el ayuntamiento de Fontanilles presento un recurso contra la ampliación del entorno de protección arqueológico ya que consideraba que este hecho impedía la instalación de explotaciones ganaderas en un municipio de características muy vinculadas al sector primario ${ }^{31}$ y según el Diari de Girona, el Tribunal Superior de Justicia de Catalunya admitía a trámite un recurso contencioso administrativo del promotor de una explotación porcina, cuya construcción había sido parada por la Generalitat por situarse dentro del espacio de protección del BCIN, y que se sumaba a otros recursos presentados por algunos de los ayuntamientos de la zona y de diversos particulares ${ }^{32}$.

27. RESOLUCIÓ CLT/4004/2006, de 24 de novembre, per la qual s'incoa expedient de mofificació de la delimitació de l'entorn de protecció del bé cultural d'interès nacional, en la categoria de zona arqueològica, del Conjunt arqueològic d'Ullastret (Ullastret, Serra de Daró, Forallac i Fontanilles, al Baix Empordà) i sobre un període d'informació pública. Diari Oficial de la Generalitat de Catalunya, 11.12.2006, 4.777, p. 51.920.

28. "Els Clots de Sant Julià tindran un entorn amb tres nivells de protecció". El Punt, 10.01.2007.

29. "La Fundació territorio i Paisatge s’interessa per la protección dels Clots de Sant Julià". El Punt, 29.07.2007.

30. "Un centenar de persones celebren la declaració del poblat ibèric d’Ullastret com a Bé Cultural d'Interès Nacional". El portal informatiu de Televisió de Catalunya, Catalunya Radio. 02.12.2006.

31. "Fontanilles no vol que s'ampliï el jaciment d'Ullastret perquè perjudica les granes". El Punt, 18.01.2007.

32. "Admeten el recurs del promotor de la granja de porcs en el BCIN d'Ullastret". Diari de Girona, 30.09.2007. 
También el ayuntamiento de Forallac interpuso un contencioso que fue admitido a trámite por el Tribunal Superior de Justicia de Cataluña ${ }^{33}$.

En ese mismo año, el conflicto sobre la instalación de la planta de residuos de la construcción en Forallac no había remitido. Vecinos de Forallac habían recogido cerca de un millar de firmas contra la instalación de la planta de tratamiento de residuos y presentado alegaciones a su autorización ${ }^{34}$.

En el año 2008 se admitía a trámite un recurso administrativo del ayuntamiento de Forallac contra una resolución del Departament de Cultura de la Generalitat de 19 de octubre de 2007 mediante la cual se declaraba espacio de protección arqueológica la zona del Puig d'en Torró/Clots de Sant Juliàa ${ }^{35}$. Según consta en los medios de comunicación la ampliación del entorno de protección chocaba con los intereses del mencionado ayuntamiento que estaba interesado en la instalación de la planta de reciclaje de residuos antes mencionada en terrenos afectados por la declaración del entorno de protección ${ }^{36}$. Además del recurso planteado por el ayuntamiento de Forallac también presentaron recurso los ayuntamientos de Serra de Daró y Fontanilles ${ }^{37}$ y una agencia inmobiliaria ${ }^{38}$. Finalmente, el 3 de junio de 2008 otro acuerdo de gobierno de la Generalitat ${ }^{39}$ aprobaba la modificación de la delimitación del entorno de protección iniciada con la resolución CLT/404/2006.

La polémica se trasladó al ámbito parlamentario catalán, donde un diputado de la oposición interpuso una batería de preguntas al Conseller de Cultura y denunciaba, según su parecer, la falta de diálogo de la Conselleria con los ayuntamientos de los municipios afectados y el hecho que esta Conselleria atendió solamente en la protección de los Clots de Sant Julià la postura de "una entidad supuestamente conservacionista, pero con

33. ANUNCI de la Secció Tercera de la Sala Contenciosa administrativa del Tribunal Superior de Justícia de Catalunya, sobre admissió a tràmits d'un recurs (ex. 22/2007). Diari Oficial de la Generalitat de Catalunya, 15.02.2007, 4.822, p. 5.477.

34. "Recullen un miler de signatures contra les dies plantes de tractament de runes de Forallac". El Punt, 11.05.2007.

35. EDICTE de 27 de març de 2008, pel qual es notifica l'admissió a tràmit del recurs contenciós administratiu 3/2008. Diari Oficial de la Generalitat de Catalunya, 8.04.2008, 5.106, p. 26.862.

36. "El tribunal Superior de Justícia admet a tràmit un recurs contra la protección dels Clots de Sant Julià”. El Punt, 09.04.2008.

37. "La Fundació territorio i Paisatge s’interessa per la protección dels Clots de Sant Julià". El Punt, 29.07.2007.

38. "El TSJC anul-la la declaració de BCIN d'Ullastret per un defecte de forma”. El Punt, 23.05.2009, p. 30 .

39. ACORD GOV/94/2008, pel qual es modifica la delimitació de lentorn de protecció del bé cultural d'interès nacional, en la categoria de zona arqueològica, del Conjunt arqueològic d'Ullastret. Diari Oficial de la Generalitat de Catalunya, 6.6.2008, 5.147, p. 43.592. 
responsables domiciliados en Barcelona y con intereses urbanísticos en la zona” ${ }^{40}$

En mayo de 2009 el Tribunal Superior de Justicia de Catalunya admitía el recurso planteado por los ayuntamientos de Serra de Daró y Fontanilles y por una agencia inmobiliaria estimando que el acuerdo mediante el cual se declaraba el conjunto arqueológico de Ullastret como BCIN se había tomado fuera de plazo al haber superado los 18 meses de que disponía la Generalitat para su declaración ${ }^{41}$. Como respuesta, la Generalitat de Catalunya recurrió la sentencia en el mes siguiente ${ }^{42}$.

\section{DIVERSIFICACIONES DE LAS DISCREPANCIAS PATRIMONIALES}

Con los tres casos expuestos hemos querido mostrar como la patrimonialización de un espacio remite a numerosas y diversas experiencias, a menudo contradictorias y conflictivas.

En el ejemplo de la playa de Sant Pol de Mar por un lado está la voluntad de un grupo de personas de convertir la playa en una especie de museo al aire libre, con embarcaciones restauradas y ligeramente transformadas según un criterio de autenticidad marinera basado en las velas latinas. Pero por otro lado está el sector de la población que siente la playa como parte de su vida y su identidad y que patrimonializa también el paisaje frente a los intentos de transformación para adaptarlos a las necesidades de ciertas infraestructuras o el uso turístico del espacio litoral. Finalmente está la posición del gobierno municipal y las personas que apoyan el proyecto de renovación del frente marítimo de la población con la protección de la línea de ferrocarril y el paseo marítimo, como elemento de dinamización turística del municipio. Hemos apuntado en otro lugar (Carbonell, 2009) que detrás de este conflicto aparece la adscripción de la gente "de dentro" frente la gente "de fuera", a pesar éstos últimos de vivir habitualmente en el pueblo. Es un tema que no tenemos espacio para desarrollar aquí. Lo que con este ejemplo hemos querido señalar es la multiplicidad de actores y posicionamientos que aparecen en un proceso de apropiación patrimonial de un espacio público, en este caso una playa urbana.

El segundo ejemplo trata de la patrimonialización del Cap de Creus como espacio natural. En este caso, la legitimación proviene de la existencia de un parque natural que es percibido por sus gestores políticos como incompatible con la permanencia de una urbanización turística, a pesar del valor arquitectónico, histórico y paisajístico que algunos expertos observan en el conjunto, además del uso de refugio de embarcaciones

40. Diari de Sessions del Parlament de Catalunya, Sèrie C, núm. 516, 11.03.2009, p. 11.

41. "El TSJC anul-la la declaración de BCIN d'Ullastret per un defecte de forma”. El Punt, 23.05.2009, p. 30 .

42. “Cultura recorre l’anul-lació del BCIN d'Ullastret i diu que mai ha rebutjat parlar-ne". Diari de Girona, 14.06.2009. 
en días de temporal de mar que los pescadores locales realizaban de su embarcadero. Pero las valoraciones estéticas y prácticas de los arquitectos y pescadores que se oponían a la demolición del conjunto vacacional de Club Med no sirvieron de freno ante la demolición solicitada por los naturalistas emparados en la existencia de leyes destinadas a la protección de determinados espacios naturales y el aplauso de la mayoría de la sociedad que veía en esa demolición una operación ejemplarizante. Todo ello, además, en clara contradicción con la permanencia de una política urbanística que, mientras se ceba con un discreto conjunto de pequeñas construcciones de una sola planta, permite en buena parte del litoral la edificación de grandes estructuras de hormigón de más que cuestionable calidad estética. A través de este caso hemos querido mostrar un ejemplo de protección del patrimonio natural puesto en duda por una minoría que, de todos modos, pone de relieve lo conflictivo de cualquier operación patrimonial. Si en el primer caso se planteaba quien estaba legitimado para patrimonializar la playa, en este caso lo que se plantea es qué es y qué no es patrimonio.

En tercer lugar, con el ejemplo del poblado ibérico de Ullastret y la ampliación del área protegida por la declaración de BCIN, a diferencia del caso anterior, nos encontramos con una oposición muy extendida en el territorio afectado, oposición que proviene de la mayoría de ayuntamientos concernidos, además algunos particulares que ven perjudicados sus intereses y que reivindican el derecho de seguir expandiendo una actividad ganadera que llevan desarrollando desde hace décadas. De todos modos, a diferencia de los casos anteriores, esto se produce en una zona con una larga relación con el patrimonio cultural, puesto que se trata de un importante yacimiento que tiene un museo abierto al público desde hace cincuenta años y que, como muestran las estadísticas, constituye un elemento dinamizador del turismo cultural nada desdeñable. Se observa, además, como ciertos alcaldes y diputados ponen en duda la legitimidad de quienes apoyaron la declaración de BCIN, pasando por alto el criterio académico de la mayoría de los expertos, y acusando a sus partidarios de ser gente de Barcelona y de moverse por intereses espurios.

Los tres ejemplos que hemos presentado consideramos que son indicativos de la situación actual de la implicación de la sociedad en los procesos de patrimonialización. En el caso concreto del ámbito que analizamos aquí, la patrimonialización de espacios, en los últimos años la sociedad se ha manifestado y ha actuado e intervenido de forma notable. Aunque en algunas ocasiones las intervenciones en los procesos patrimoniales puedan ser debidas a intereses económicos de carácter privado, en la mayoría de los casos responden a voluntades de participar en las decisiones patrimoniales. A través de la movilización ciudadana organizada, los nuevos movimientos sociales han incorporado a sus reivindicaciones el patrimonio cultural, especialmente al vinculado a territorios y espacios. Pero, al mismo tiempo, últimamente se están incrementando las manifestaciones 
de forma pública de las múltiples y diversas visiones de las conceptualizaciones patrimoniales, y también de las discrepancias que ello conlleva. Estas múltiples propuestas patrimoniales, resultado de formas diferentes de analizar la sociedad y de proyectar su futuro, además de constituir una interesante forma de expresión y de participación directa en decisiones de carácter público, aportan una importante riqueza y diversidad a la conceptualización del patrimonio cultural y lo convierten en un espacio de debate para la interpretación de nuestras problemáticas actuales y futuras. 


\section{REFERENCIAS BIBLIOGRÁFICAS}

AA.VV. (2005) Debat Costa Brava Congrés: un futur sostenible. Girona: Demarcació de Girona del Collegi d'Arquitectes de Catalunya.

ALCALDE, G.; AQUILUÉ, X.; BURCH, J.; MARTÍ, E. ; ROJAS, A. y TREMOLEDA, J. (2011) "Knowledge and use of the archaeological heritage of the Costa Brava by tourist office users". En Llorenç. Prats (ed.), Researching Coastal and Resort Destination Management. Cultures and Histories of Tourism. Bloomington: Palibrio, pp. 204-218.

ALEGRET, Juan Luis y NADAL, Berta (1987) Les confraries de pescadors. La dimensiósocial de la pesca a Catalunya. Barcelona: Direcció General de Pesca Marítima, Departament d’Agricultura, Ramaderia i Pesca, Generalitat de Catalunya.

CARBONELL, Eliseu (2010) "Patrimonialización de un paisaje marítimo: De la arena de la playa a la arena política". Pasos. Revista de turismo y patrimonio cultural, 8(4), pp. 569-581.

CATALUNYA TURÍSTICA EN XIFRES 2010 (2011). Barcelona: Generalitat de Catalunya. http://www.gencat.cat/diue/ambits/turisme/observatori turisme/estadistiques/xifres/ index.html

MARTÍN, Aurora (1997) Guies del museu d'Arqueologia de Catalunya. Ullastret. Girona: Museu d'Arqueologia de Catalunya.

MARTÍNEZ, Pelayo Campamento de turismo privado propiedad del Club Mediterranée, Arxiu Històric del Col-legi d’Arquitectes de Catalunya, Demarcació de Girona. Fons Pelayo Martínez.

MONTIEL, Antonio (2004) "Moviments socials i patrimoi cultural". En AA.VV., Patrimoni i societat. València: Universitat de València, pp. 79-99.

MONTIEL, Antonio (2008) "Patrimoni cultural i nous actors socials". En XX Jornades de la Xarxa de Museus Locals de la Diputació de Barcelona. Barcelona: Diputació de Barcelona, pp. 45-59.

MUSQUERA, Silvia (2004) "El Club Mediterranée. Intervenció en el paisatge del cap de Creus als anys 60". Annals de l'Institut d'Estudis Empordanesos, 37, pp. 311-342.

NEL.LO, Oriol (ed.) (2003) Aquí, no! Els conflictes territorials a Catalunya. Barcelona: Empúries.

NOGUÉ, Joan (2010) Paisatge, territori i societat civil. València: Edicions 3 i 4.

ROIGÉ, Xavier y FRIGOLE, Joan (eds.) (2010) “Introduction”. En Roigé, X. y Frigole, J. (eds.) Constructing Cultural and Natural Heritage. Girona: Institut Català de Recerca en Patrimoni Cultural. 
TERRADAS, Ignasi (2004) "La contradicción entre identidad vivida e identificación jurídico-política”. Quaderns de l'Institut Català d’Antropologia, 20, pp. 63-79. 